\title{
Development of Hardware In the Loop System (HILS) for Hydraulic Excavator
}

\author{
Tae-Hyeong Lim, Hyun-Chul Cho, Hong-Sun Lee, and Soon-Yong Yang
}

\begin{abstract}
Hydraulic excavators have been popular devices in construction field because of its multi-workings and economic efficiency. The mathematical models of excavators have many nonlinearities because of nonlinear opening characteristics and dead zone of main control valve, oil temperature variation, etc. Actual test is needed when new component or control algorithm is developed but many restrictions exist. Hydraulic circuit of excavator is too complex to make models mathematically but dynamic equation of manipulator has made good progress in previous studies. Basic concept of HILS and AMESim model of hydraulic components is contained in this paper.
\end{abstract}

Index-Hydraulic Excavator, HILS, Paper map, AMESim.

\section{INTRODUCTION}

$\mathrm{H}$ ydraulic excavator have been popular device in construction field because of its multi-working and economic efficiency. The application of this complex device will be extended manufacture, agriculture, undersea etc.

But its operating need very difficult skill because operator has to operate joysticks and pedals consequently. So accuracy of work is influenced by operator's skill. But environment of work is poor and difficult skill bring about feeling fatigued fast. Autonomous excavator can be a kink of solution about previous problems and many researches have been achieved by many researchers. British Columbia university in Canada, Carnegie Mellon university in USA and Sydney university in Australia have field robot center and have made a special studies with excavator and many construction equipment makes have prototype or autonomous excavator in part.

The paper map in field robot with excavator made before in my laboratory show that $56 \%$ of papers focus in modeling of attachment (Boom, Arm, Bucket) using Lagrange Euler equation and applying control algorithms but hydraulic circuit

This work was supported by the Korea Science and Engineering Foundation (KOSEF) through the research center for machine parts and material processing at University of Ulsan and Hyundai Heavy Industry.

T.H. Lim is with Department of Mechanical \& Automotive Engineering, University of Ulsan, Korea (corresponding author to provide phone: +82-52-259-2731; e-mail: bulbaram@ mail.ulsan.ac.kr)

H. C. Cho is with e-Vehicle Technology, University of Ulsan (e-mail: cmcchc@msn.com).

H.S. Lee is with the Department of Construction Equipment, Hyundai Heavy Industry, Korea (e-mail: hsl@hhi.co.kr).

S. Y. Yang is with School of Mechanical \& Automotive Engineering, University of Ulsan, Korea(e-mail : soonyy@ulsan.ac.kr) and valves are modeled very simply. For example, main control valves having nonlinear open area characteristics are modeled in simple variable orifice and logic valves are omitted. In many paper, researchers use robust controller in order to overcome nonlinearities created by complex open area characteristics and dead zone of valve, single acting cylinder, heavy weight of attachment. Because of many nonlinearities, experiments are positively necessary but limited by time, money, place etc.

The concept of Hardware In the Loop System(HILS) is that Hydraulic circuit having many nonlinearities is put into simulation loop but motion equation of attachments is coded in the loop using Lagrange equation. The final objective of my research is to develop of HILS for hydraulic excavator but the objective of this paper is to develop of AMESim model of hydraulic excavator. This model can be used to foreca -st excavator behavior when new components, new mechanical attachments, hydraulic circuit changes, and new control algorithm are applied. The simulator could be a kind of development platform for various new excavators.

\section{HILS FOR EXCAVATOR}

Hydraulic excavator is very popular machinery to researchers because of nonlinearities. Many of paper about excavator can be found in many journals. The search engine was IEEExplorer and ScienceDirect and 85 papers are related to my research and classified into 5 subject - motion equation and control algorithm, trajectory of end effecter, introduction new model, tele-operation, virtual environment and development of system. Fig. 1 3 shows papers according to year and nation, journal and year and subject.

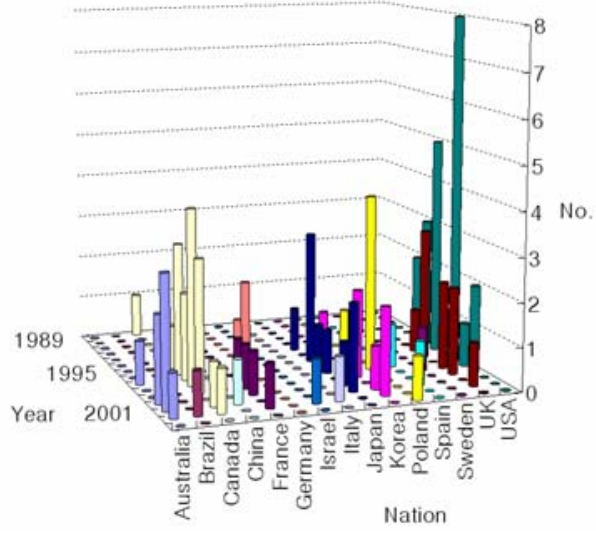

Fig. 1 Papers according to year and nation 


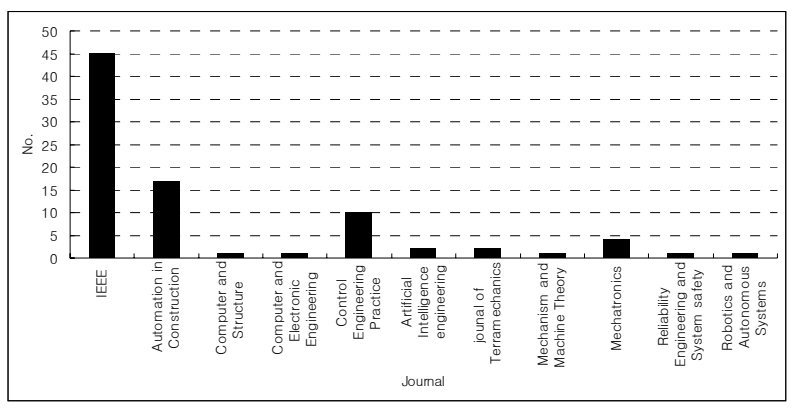

Fig. 2 Papers according to journal

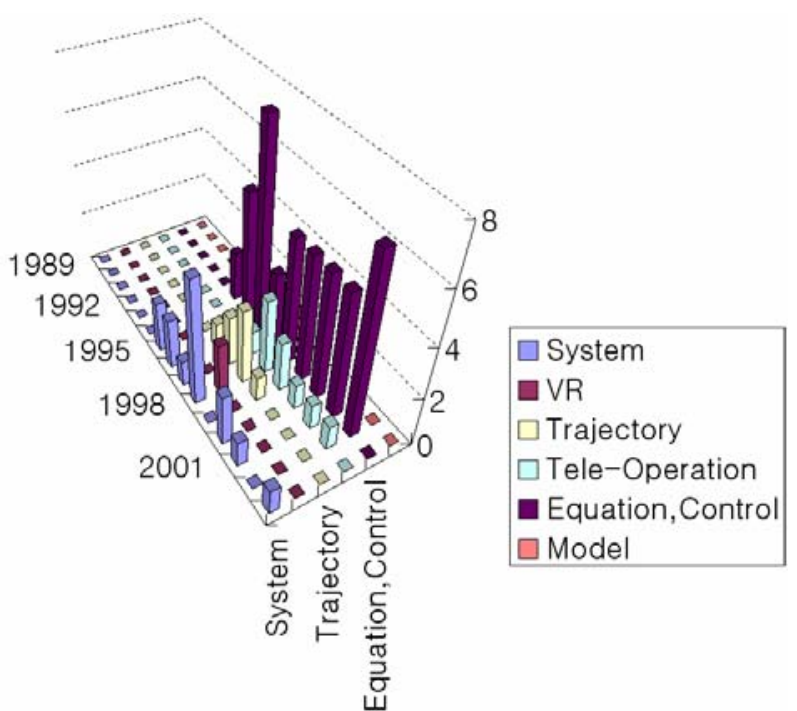

Fig. 3 Papers according to year and subject

From the analysis of paper map, motion equation of attachment using Lagrange equation is typical but hydraulic circuit isn't modeled full model because excavator has many hydraulic components and each component has strong nonlinearity.

The basic concept of HILS is that real hydraulic circuit is be put into simulation loop. For effects of inertia and gravity of attachment force operating cylinder in Fig. 4 is added to boom cylinder end.

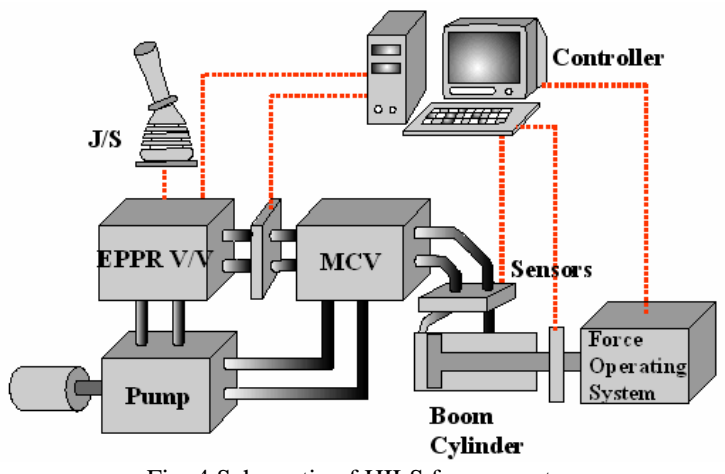

Fig. 4 Schematic of HILS for excavator

\section{EXCAVATOR MODEL}

\section{A. Attachment}

Attachment is modeled boom, arm, bucket except swing and drive and excavator model is 5 ton of Hyundai Heavy Industry.

Fig. 5 shows the coordinate systems of excavator and motion equation was established by Lagrange equation.

$$
\sum_{j=1}^{n} H_{i j} \ddot{q}_{j}+\sum_{j=1}^{n} \sum_{k=1}^{n} h_{i j k} \dot{q}_{j} \dot{q}_{k}+G_{i}=Q_{i}, i=1, \ldots, n
$$

$H_{i j} \ddot{q}_{j}$ is inertia torque including interaction torque by off diagonal element of attachment inertia tensors, $h_{i j k} \dot{q}_{j} \dot{q}_{k}$ is Coriolis and centrifugal effects and $G_{i}$ is gravity torque.

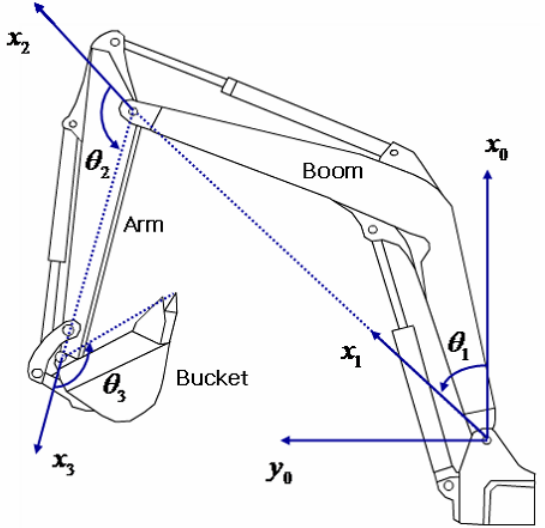

Fig. 5 Coordinate system

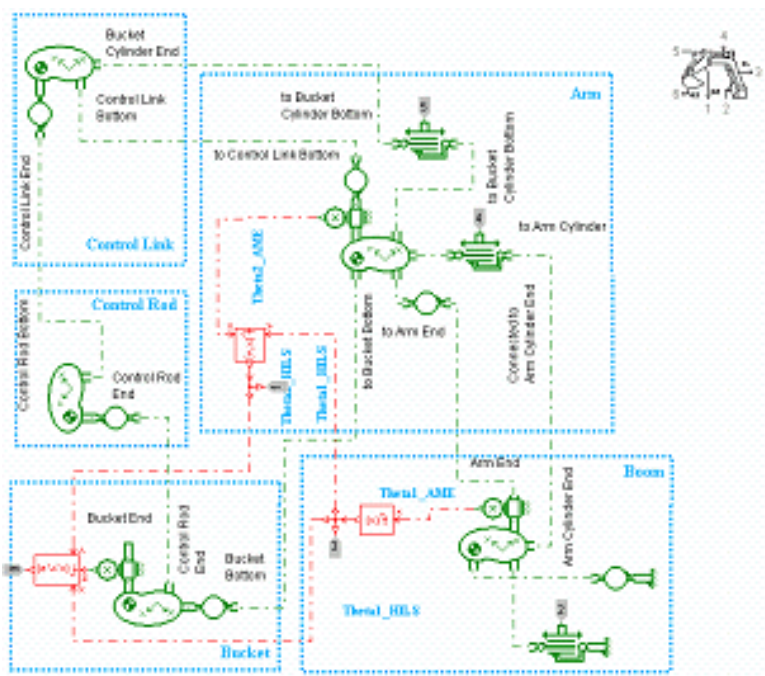

Fig. 6 AMESim model of attachment

Fig. 3 present AMESim model of attachment. The supercomponent of attachment is shown right and upper part in fig. 3 and this contain the rest components. Each component contain link's characteristic-length, mass, inertia etc. The coordinates in fig. 2 are contained the attachment supercomponent. The inputs of supercomponents are force of cylinder and outputs are angular displacement of boom, arm and bucket. 


\section{B. Hydraulic circuit}

Main pump operated by engine make two type of pressures that main pressure work each cylinder and pilot pressure work spool of main control valve by operating joystick. If operator handle joystick or lever, pilot pressure push the spool of MCV, the rate and direction of flow is decided by spool displacement and direction and flow rate can decide of direction and velocity of cylinder. Working area is assumed 2D in this paper, hydraulic circuit can be simplified like fig. 7. Because boom up and arm dump need much flow rate, join of flow rate between boom 1 valve and boom 2 valve, arm 1 valve and arm 2 valve.

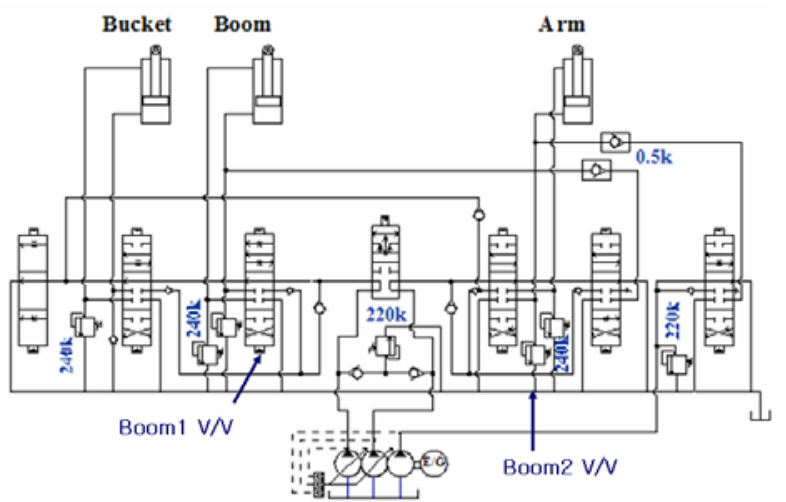

Fig. 7 Simplified hydraulic circuit

\section{Joystick}

The role of joystick is supplying pilot pressure to MCV by operate angle. The AMESim model of joystick is shown in fig. 8. components in dotted square are contained supercomponent in left hand side. Operating of joystick is assumed to signal between -1 to 1 and pilot pressure to $\mathrm{A}, \mathrm{B}$ port is directly proportional to signal. The input signal to joystick model is fig. 9 (a) and pilot pressure at port A, B is (b). In fig. 9, pilot pressure response is proportional and delay is rare.

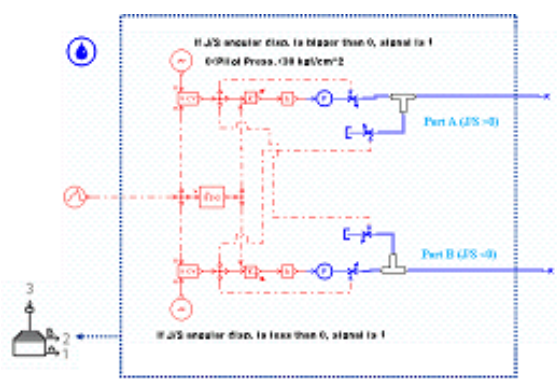

Fig. 8 AMESim model of joystick

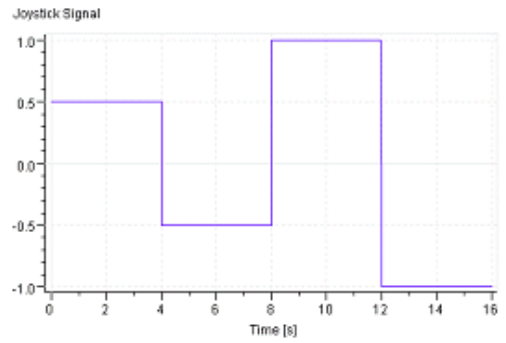

(a) Input signal

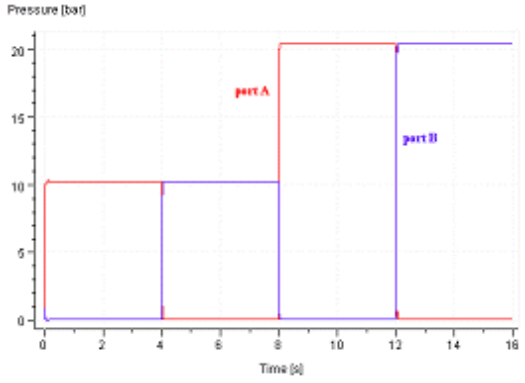

(b) Pilot pressure at A, B port

\section{Pump}

Fig. 9 Result of joystick model

The pump assembly consist of 2 variable pump for main pressure and 1 fixed pump for pilot pressure. Variable pump has control algorithm for energy saving, this can be characterized to $\mathrm{P}-\mathrm{Q}$ diagram. The AMESim model of pump assembly is shown in fig. 10. Various P-Q diagram can be tested in this model easily because $\mathrm{P}-\mathrm{Q}$ diagram is inserted by text file. For verification of pump model, input and output P-Q characteristics are shown in fig. 11 . The solid line is input and dotted line is output. This pump model is verified with valve and cylinder.

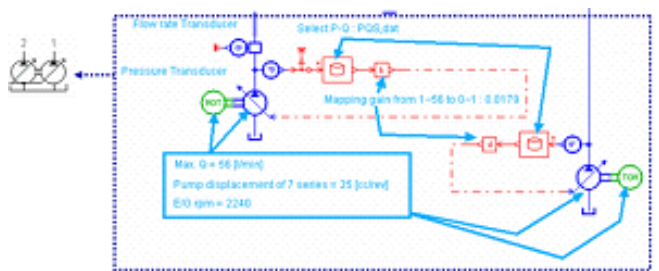

Fig. 10 AMESim model of pump

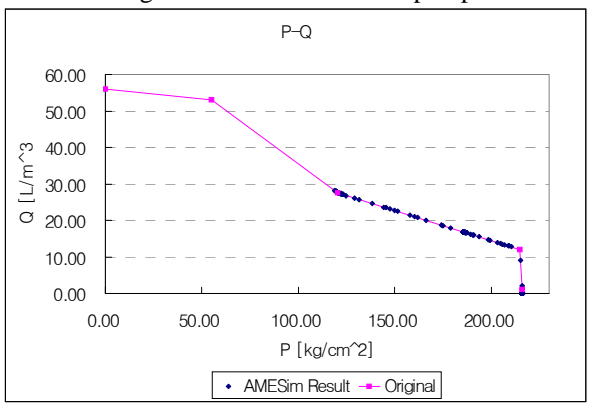

Fig. 11 Result of pump model

\section{Boom 1 valve}

Boom 1 valve, decide direction and velocity of boom cylinder mainly, is modeled 6 port 3 position valve. The spool displacement-Open area diagrams contain many nonlinearities dead zone, saturation and unproportional characteristic. These nonlinear diagrams are put into model text file. Fig. 12 show open area diagrams. The velocity of boom cylinder at up and down will be different because of nonsymmetrical diagram. Fig. 13 is AMESim model of boom 1 valve. The components in dotted square are packed into super- component in left hand side in fig. Fig. 14 show that spool displacement in various spring stiffness. 


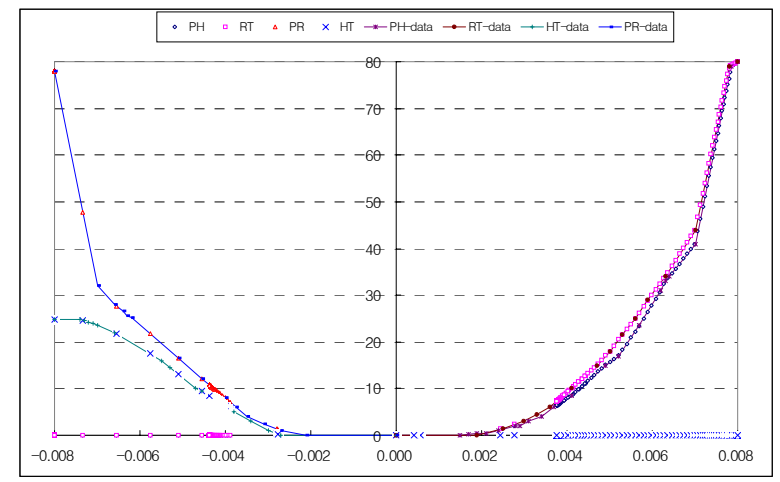

Fig. 12 Spool displacement-Open area diagram of boom 1 valve

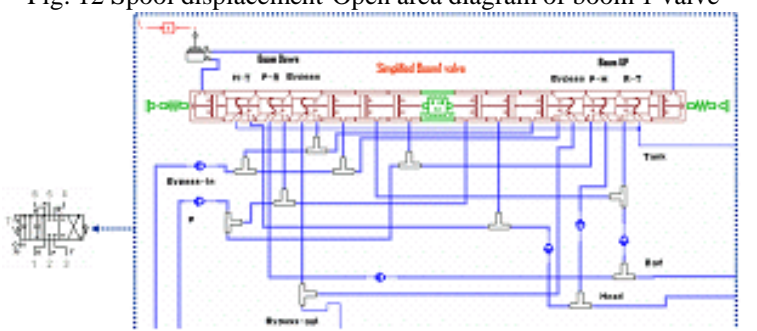

Fig. 13 AMESim model of boom 1 valve

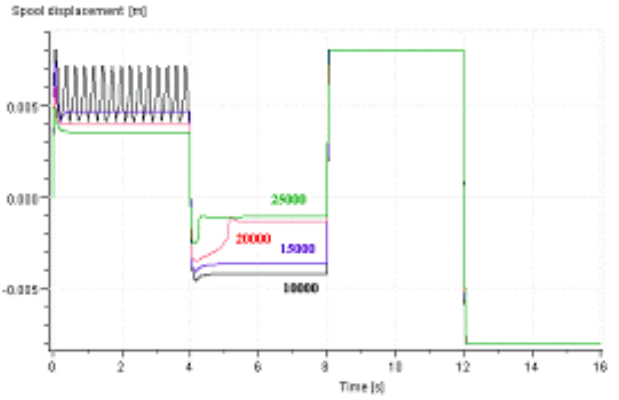

Fig. 14 Spool displacement in variable stiffness

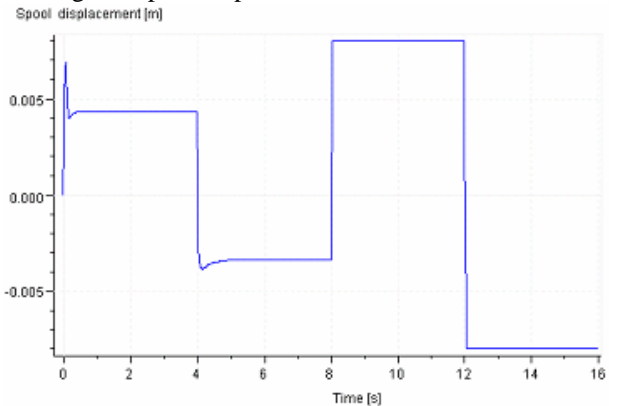

Fig. 15 Spool displacement at stiffness 17000

Stiffness variation has influence upon valve displacement. Too low stiffness produce oscillation of spool and errors between up and down are different to each other. 17000 make the error to minimum and spool displacement is shown in fig. 15 . The displacement error at boom up is $0.316[\mathrm{~mm}]$, at boom down is $0.61[\mathrm{~mm}]$.

\section{Boom 2 valve}

The role of boom 2 valve is supply flow rate to boom cylinder at boom up. The boom 2 valve model has same structure with boom 1 valve model and different open area diagram. 20000 make the error to minimum and spool displacement is shown in fig. 16. The displacement error at boom up is $1.02[\mathrm{~mm}]$

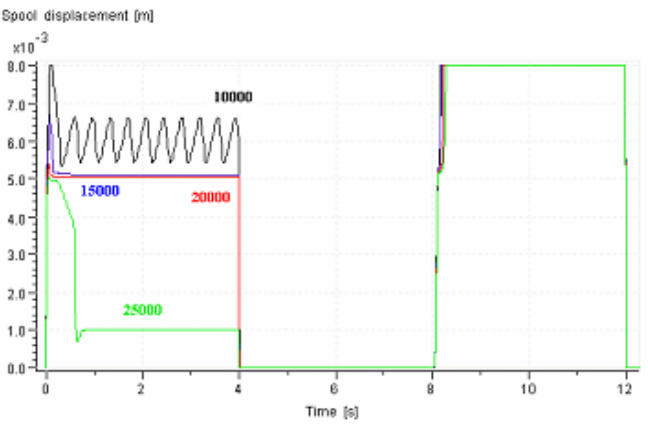

(a) Spool displacement in variable stiffness

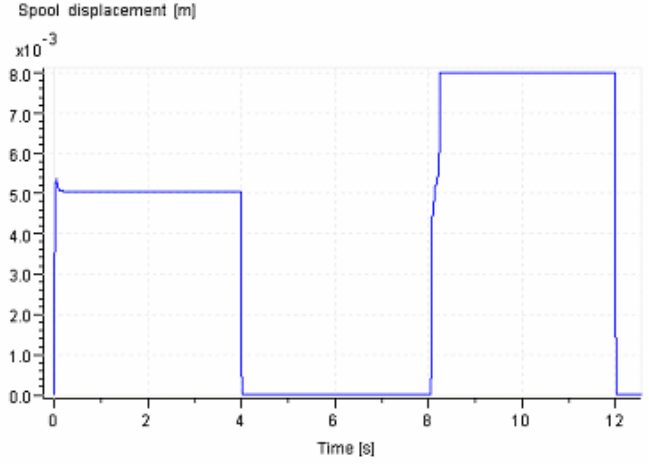

Fig. 16 (b) Spool displacement at stiffness 20000

\section{Arm 1 valve}

Arm 1 valve, decide direction and velocity of Arm cylinder mainly, has same structure with boom 1 valve model and different open area diagram. 20000 make the error to minimum. The displacement error at arm dump is $0.0534[\mathrm{~mm}]$, at arm crowd is 0.284 [mm].

\section{Bucket valve}

The final spring stiffness of bucket valve is 26000 and error at bucket dump is $0.042[\mathrm{~mm}]$, at bucket crowd is 3.17[mm].

\section{Main Control Valve (MCV)}

The main control valve block consist of previous hydraulic components(1 5) is shown in fig. 17. The working fluid through by pass go to tank and feature of circuit is similar to simpliflied circuit in fig. 7. The port relief is added to cylinder in, out port.

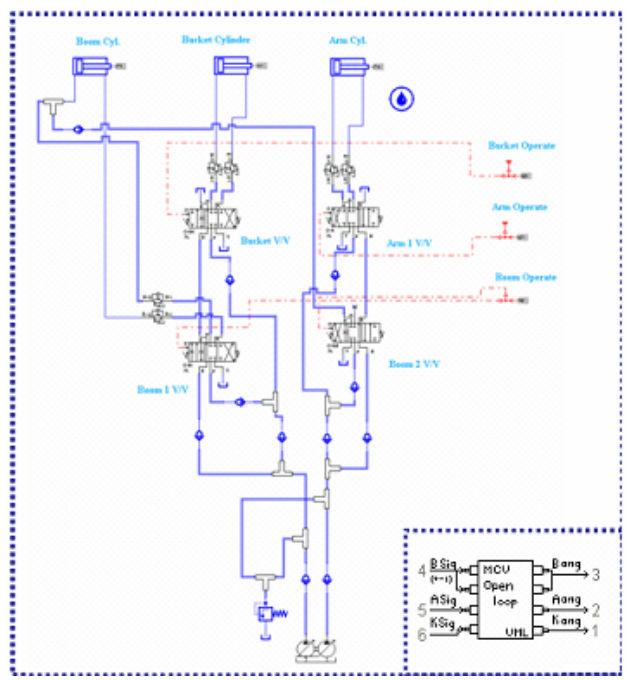

Fig. 17 AMESim model of MCV 


\section{Excavator model}

Total excavator model is constructed in fig. 18 using previous models.

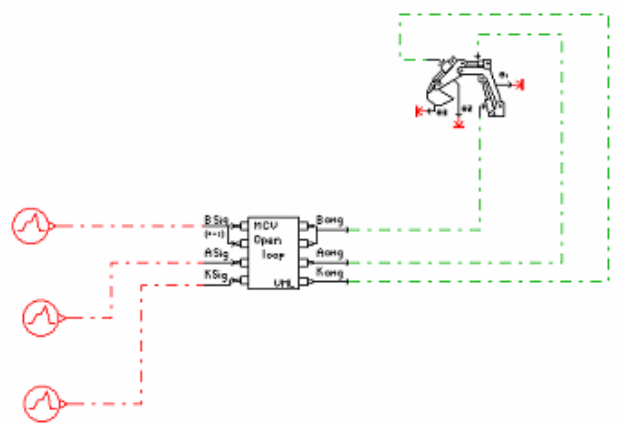

Fig. 18 AMESim model of excavator

Though stiffness tuning was done, results in complex motion is different from it at single motion. Simulation condition is that operate joystick 50 [\%] to + for 4 [sec] , 50 [\%] to -, 100 [\%] to + and 100 [\%] to - of boom, arm and bucket simultaneously. Fig. 19 show spool displacement of boom 1 valve and boom 2 valve under simulation condition. Displacement error is bigger than simple motion that is because main pressure at cylinder effect to MCV.

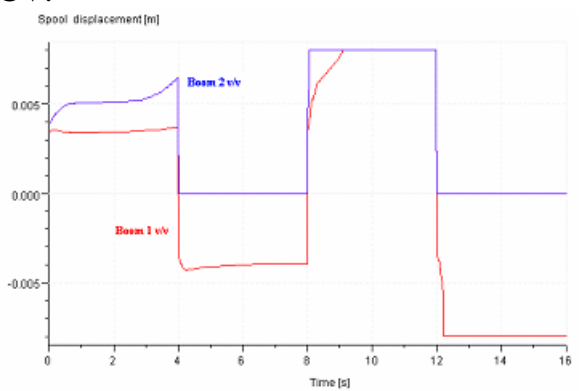

Fig. 19 Spool displacement of boom valves in complex work

\section{Closed loop type $M C V$}

Previous model has meaning as predict excavator's behavior. But spool displacement isn't proportional to pilot pressure because of effect of main pressure and nonsymmetrical open area diagram. Fixed spring stiffness can’t satisfy whole P-Q line and can't reduce displacement error.

To improve linearity closed loop type valves are proposed. Feature of closed type boom 1 valve is shown in Fig. 20. Spool displacement of closed type boom 1 valve in variable proportional gain (10,50 and 100) is shown in Fig. 21. Proportional gain 100 has reduced displacement error to 0.037 [mm] and direction didn't effect to error.

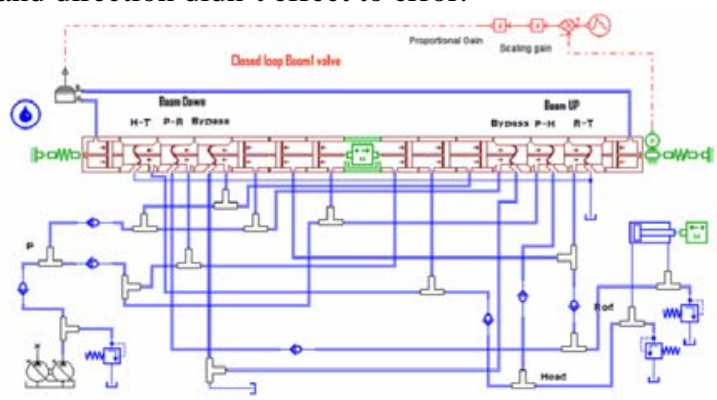

Fig. 20 AMESim model of closed loop type boom 1 valve

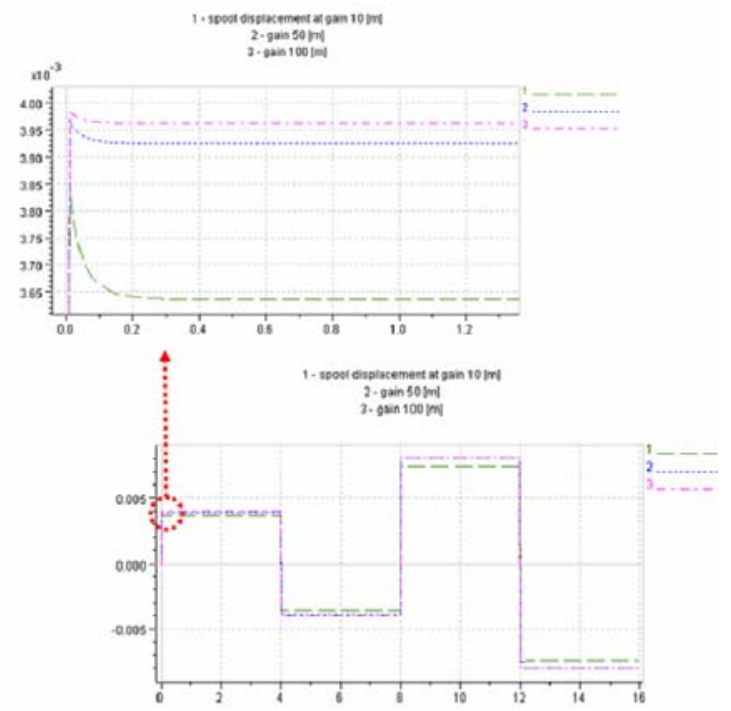

Fig. 21 Spool displacement in variable proportional gain

\section{E. Simulation results}

Joystick is Fig.22, Fig. 23 25 are characteristics of closed type MCV's.

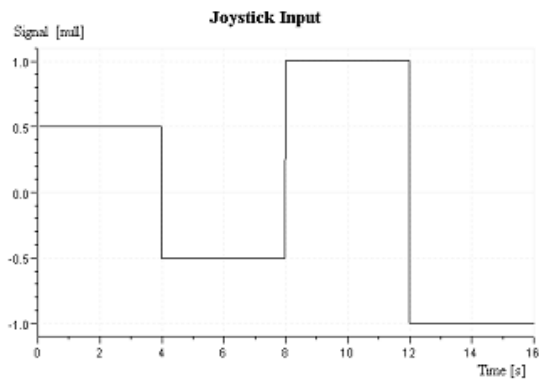

Fig. 22 Joystick input
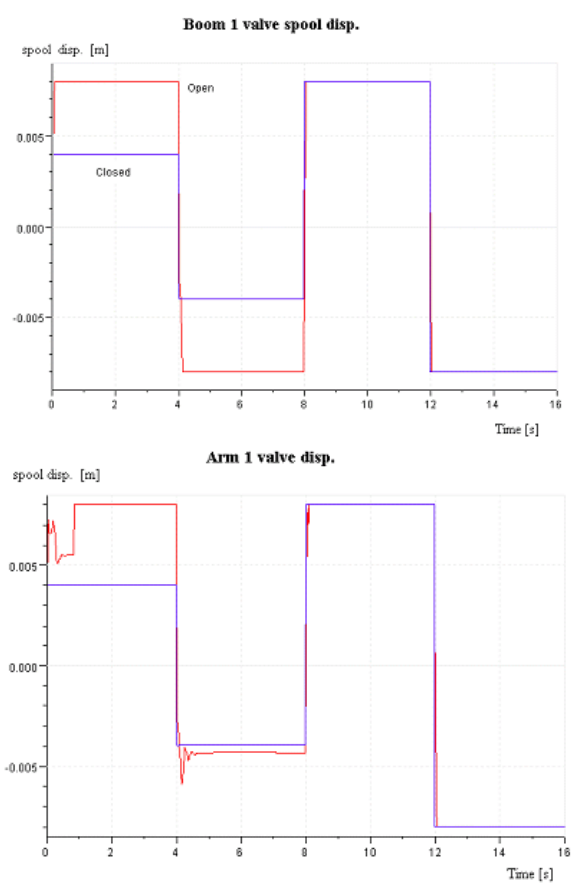


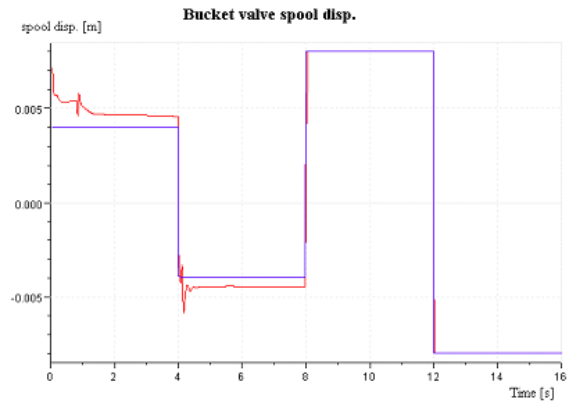

Fig. 23 Spool displacement of MCVs
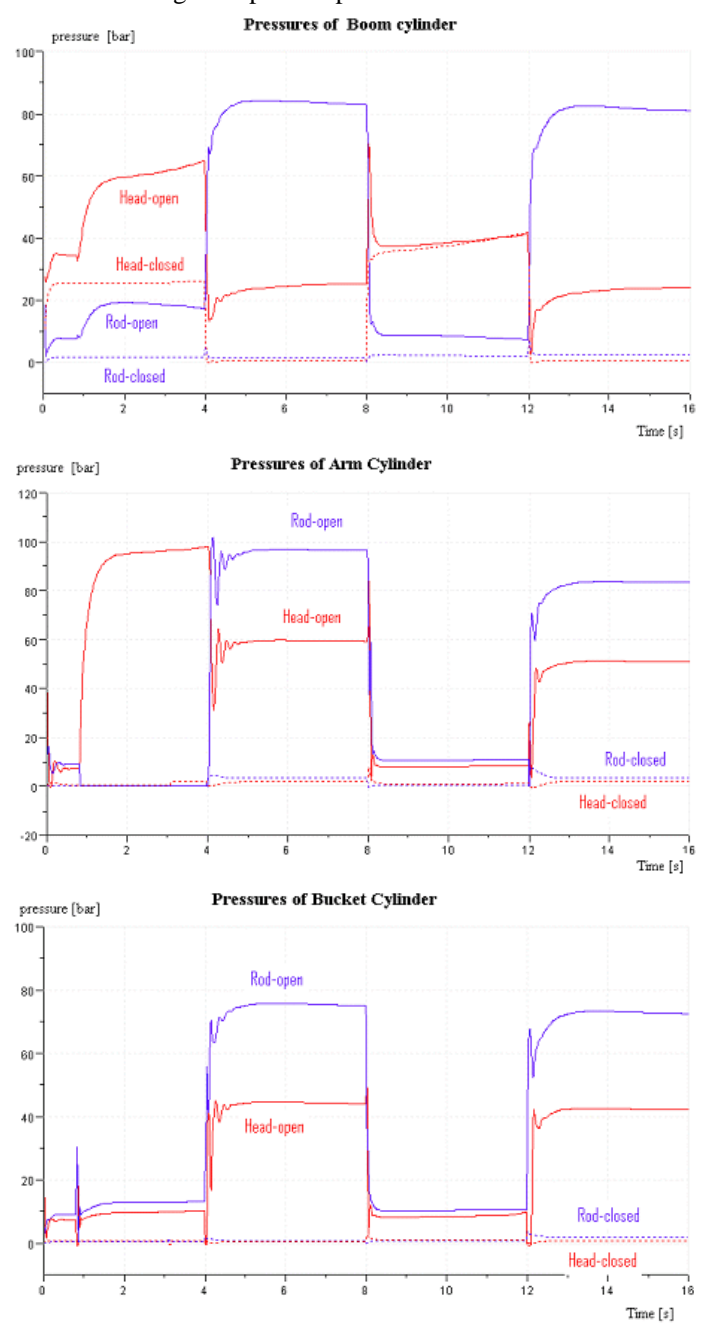

Fig. 24 Pressures at each cylinder Angular disp. of each attatchmen

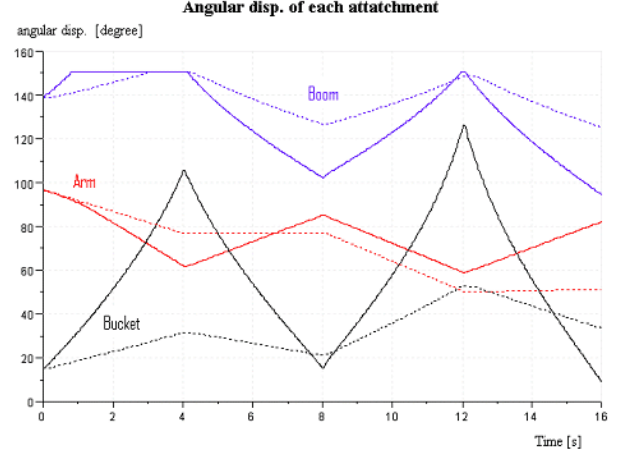

Fig. 25 Angular displacement of attachment

\section{CONCLUSION AND FUTURE WORK}

From the analysis of paper map, the concept of HILS for hydraulic excavator is proposed in this paper. Attachment, hydraulic components and circuit of excavator are modeled with AMESim. For boom 1 valve error at boom up is $0.316[\mathrm{~mm}]$, boom down is $0.61[\mathrm{~mm}]$ with stiffness 17000 . In case of boom 2 valve, error at boom up is 1.02 [mm] with stiffness 20000. Arm 1 valve, error at arm dump is 0.0534 , arm crowd is 0.284 [mm] with stiffness 20000. In bucket valve, error at bucket dump is $0.042[\mathrm{~mm}]$, at bucket crowd is $3.17[\mathrm{~mm}]$ with stiffness 26000 . So, constant spring stiffness can't satisfy accuracy of spool displacement for all condition. To improve error closed loop type MCVs are proposed. Error is reduced to 0.037 [mm] and is not influenced by direction but operator's feeling is not tuned up in closed loop type valves. The AMESim model for total excavator will be used to verify new control algorithm or new component. Under being many limit to make an experiment with real excavator, this AMESim model will play an active part in simulator or test bench.

\section{REFERENCES}

[1] T. R. Kane, "Dynamics : Theory and Applications", McGraw-Hill, 1985.

[2] R. P. Paul, "Robot manipultors : Mathematics, Programming, and Control", The MIT Press, 1981.

[3] J. Watton, " Fluid Power Systems, Prentice Hall, 1989.

[4] S. Y. Yang etc. "A Study on Trajectory Tracking Control of Field Robot", ICASE, Vol8, No.9, 2002.

[5] “ AMESim User's Manual” , IMAGINE, 2000. 